\title{
МЕТОДИЧЕСКИЕ АСПЕКТЫ ОЦЕНКИ ЭФФЕКТИВНОСТИ ИНВЕСТИЦИОННОГО ПОРТФЕЛЯ КОММЕРЧЕСКОЙ ОРГАНИЗАЦИИ
}

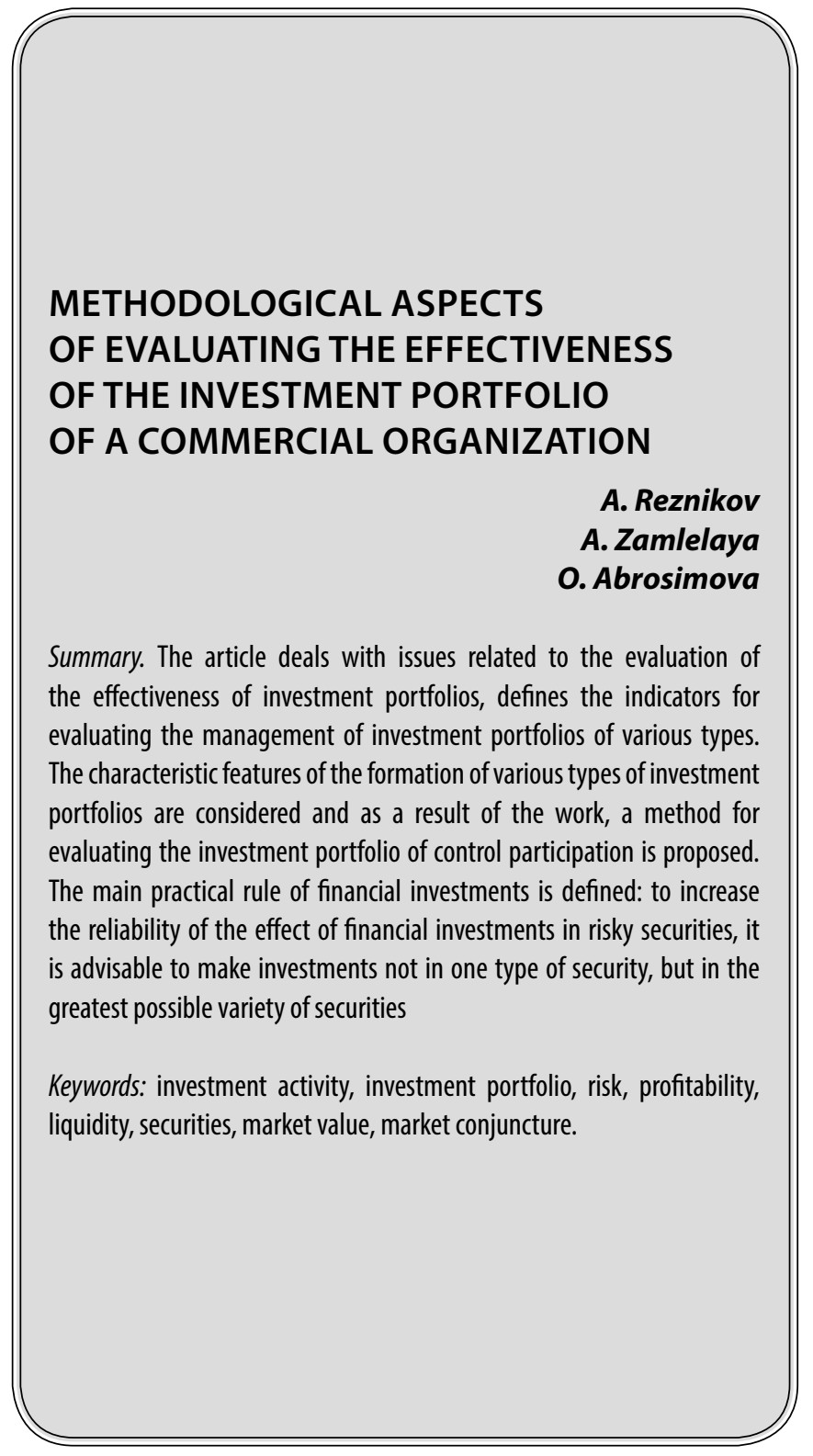

$\Pi$ роблеме формирования инвестиционного портфеля отведено одно из ведущих мест в современной экономической теории и практики. Этот аспект обуславливается их актуальностью в условиях развитого рынка. Однако условия экономики нашего государства не предоставляют возможности в полной мере использовать общие положения теории портфельного инвестирования и арсенал инвестиционных стратегий, который сформирован на территории западных стран. К ряду основных факторов, которые определяют
Резников Андрей Валентинович

Д.э.н., профессор, Егорьевский технологический институт (филиал) Московского государственного технологического университета «СТАНКИН», Московская область, г. Егорьевск reznikoff_av@mail.ru

Замлелая Анна Тихоновна

К.э.н., дочент, Егорьевский технологический институт (филиал) Московского государственного технологического университета «СТАНКИН», Московская область, г. Егорьевск zamlelaia@mail.ru

Абросимова Ольга Сергеевна К.э.н., дочент, Егорьевский технологический институт (филиал) Московского государственного технологического университета «СТАНКИН», Московская область, г. Егорьевск pmabros@list.ru

Аннотация. В статье рассматриваются вопросы, касающиеся оценки эффективности инвестиционных портфелей, определяются показатели оценки управления инвестиционными портфелями различных типов. Рассмотрены характерные особенности формирования различных видов инвестиционных портфелей и как результат работы предложена методика оценки инвестиционного портфеля контрольного участия. Определено главное практическое правило финансовых инвестиций: для повышения надежности эффекта от финансовых инвестиций в рискованные ценные бумаги целесообразно делать вложения не в один вид ценной бумаги, а в возможно большее разнообразие ценных бумаг

Ключевые слова: инвестиционная деятельность, инвестиционный портфель, риск, доходность, ликвидность, ценные бумаги, рыночная стоимость, рыночная конъюнктура.

формирование фондового портфеля, относятся следующие:

- приоритеты целей инвестирования, реализация которых обусловливает выбор конкретного типа инвестиционного портфеля;

- степень диверсификации инвестиционного портфеля;

- необходимость обеспечения требуемой ликвидности портфеля;

- уровень и динамику процентной ставки; 
- уровень налогообложения доходов по различным финансовым инструментам.

Для инвестирования, формирование инвестиционного портфеля вполне может осуществляться, основываясь на различных соотношениях дохода и риска, которое является характерным для какого-то определенного типа портфеля. В непосредственной зависимости от выбранного типа портфеля происходит отбор ценных бумаг, которые в свою очередь обладают определенными инвестиционными свойствами. Стоит отметить, что после того, как инвестиционный портфель будет сформирован, следует выполнить анализ его эффективности. В рамках данной работы будет рассмотрен портфель контрольного участия, а также неконтролирующий портфель [1].

Проведение анализа инвестиционного портфеля коммерческой банковской организации начинается непосредственно с изучения его структуры. Составляющие данной структуры представлены портфелем контрольного управления, неконтролирующим портфелем, а кроме того и портфелем простых инвестиций. Следовательно, они соответственно составляют более 50, более 20 и менее 50 , а также менее $20 \%$ общего количества акций эмитента, обладающих правом голоса [2].

В процессе проведения анализа эффективности вложений в портфель контрольного участия, а также вложений в неконтролирующий портфель необходимо принимать во внимание то, что основная цель стратегического инвестирования заключается в управлении дочерним или зависимым акционерным обществом. Следовательно, проводить анализ эффективности операций по вложению денежных средств в портфель контрольного участия и вложению в неконтролирующий портфель следует с учетом, как текущей доходности самих портфелей, так и иных доходов, которые приносят дочерние или зависимые предприятия банковской организации.

С целью определения эффективной ставки процентов по всем элементам инвестиционного портфеля могут применяться следующие формулы:

1. В случае начисления простых процентов:

$$
V=v / I_{0} \times n=v / I_{0} \times T / t_{0},
$$

2. В случае начисления сложных процентов:

$$
V=\sqrt[n]{I / I_{0}-1}=\sqrt[n]{1+v / I_{0}-1}
$$

где

$v=I-I 0-$ доход, полученный в результате инвестирования суммы I0;
I - сумма, полученная в результате инвестирования суммы I0;

$n$ - срок инвестиционной операции в годах;

$t_{0}$ - срок инвестиционной операции в днях;

$T$ - число дней в году.

Стоит подчеркнуть, что степень определенности тех величин, которые входят в формулу доходности считается довольно значимым аспектом. В случае если текущий доход, а также цены в начале и в конце периода являются известными, то доходность признается достигнутой или же реализованной. Но при планировании инвестиций, как правило, известной является только начальная цена. Текущий доход и конечная цена для выбранного инвестиционного периода, как показывает практика, являются неизвестными. Полученные в результате проведения оценки величины являются ожидаемыми значениями. Доходность, которая получена на основе таких оценок, будет также считаться ожидаемой доходностью. Стоит отметить, что при практическом применении реальные значения этих величин вполне могут отличаться от ожидаемых величин. В связи с этим, инвестиционные решения, которые основываются на ожидаемых значениях, являются сопряжены с риском.

При проведении оценки доходности инвестиций и анализа финансового состояния организации особенное внимание требуется уделять показателю прибыли данного общества, величине дивидендов на одну акцию, а кроме того и отношению текущего курса к величине годовой прибыли на каждую акцию. Упомянутые показатели выступают в качестве базовой информации для проведения правильной оценки фактической стоимости акции.

В связи с тем, что главной целью формирования инвестиционных портфелей считается довольно длительное владение акциями дочерних и зависимых организаций, то правильным будет определить фактический уровень текущей доходности портфеля. Иными словами, требуется скорректировать показатель на темп инфляции:

$$
V_{r}=V-i / 1+i
$$

где

$V_{r}$ - реальная текущая доходность портфеля за год;

$i$ - годовой темп инфляции.

Текущая доходность говорит об абсолютном росте денежных средств кредитной организации-инвестора, а реальная текущая доходность характеризует прирост покупательной способности инвестиционных средств.

С целью снижения рисков, которые являются присуще определенному виду ценных бумаг, необходимо 
провести формирование диверсифицированного инвестиционного портфеля. Он, в свою очередь, позволит максимально сократить вероятность неполучения дохода посредством вложения в совокупность ценных бумаг различных эмитентов.

Определяется норма дохода по рассматриваемому портфелю следующим образом:

$$
V_{p}=\sum_{j=1}^{k} v_{j} \times l_{j},
$$

где

$V_{p}$ - доходность всего портфеля;

$v_{j}$ - доход на ценную бумагу ј-го вида;

$l_{j}$ - доля ценных бумаг ј-го вида в портфеле;

$k$ - число видов ценных бумаг в портфеле.

Диверсификация портфеля сокращает риск инвестиций, но при этом полностью его не исключает. Это обуславливается тем аспектом, что не представляется возможным исключить влияние систематического риска, который присущ рынку в целом. В связи с этим, в рамках проведения расчета риска инвестиционного портфеля он сопоставляется с общерыночным риском. Для проведения оценки риска диверсифицированного портфеля применяется коэффициент $\beta$, который рассчитывается по следующей формуле:

$$
\beta_{p}=\sum_{j=1}^{k} \beta_{j} \times l_{j},
$$

где $\beta_{p}$ - риск по портфелю в целом;

$\beta_{j}$ - не диверсифицированный риск ценной бумаги j-го вида.

Проводя анализ, направленный на формирование портфеля, который является наиболее оптимальным с точки зрения соотношения риска и доходности, необходимо ориентироваться на получение оптимального значения такого показателя, как Vp и коэффициента $\beta p$ менее 1 , поскольку в данном случае риск будет меньше среднерыночного.

При совершении покупки акций требуется принимать во внимание то, что источниками дохода могут быть как дивиденды, так и разница между ценой, по которой приобретается акция и ценой, по которой она через определённый период времени может быть продана. При определении доходности акций в периоде, который захватывает их реализацию, требуется провести расчет полного дохода от владения акциями:

$$
V_{a}=V+P_{s}-P_{c}-C,
$$

где $V_{a}$ — полная доходность портфеля за период;
$P_{s}$ - продажная стоимость бумаг;

$P_{c}$ - покупная стоимость бумаг;

$C$ - расходы, связанные с приобретением и реализацией бумаг.

По причине того, что в себестоимость продукта банковской организации, которая служит базой для определения цены его размещения включаются как прямые затраты, так и накладные затраты, которые в свою очередь относятся к подразделению, а кроме того и общебанковские накладные расходы, требуется производить их распределение.

В качестве наиболее оптимального метода распределения указанных затрат, которые связаны с обеспечением функционирования банковской организации, выступает метод распределения пропорционально доле работающих активов. Это объясняется тем, что они считаются источником доходов банковской организации, посредством которых и покрываются затраты, а вместе с тем и формируется прибыль.

Также при определении цены размещения активов некоторые исследователи считают необходимым принимать в расчет показатель трансфертной цены на ресурсы, по которой подразделения, привлекающие средства, продают их размещающим подразделениям. В рассматриваемом случае между привлекающим и размещающим подразделением появляется еще одно доходное структурное подразделение, которое именуется казначейством. Согласно западной практики проведения анализа, в частности методики, которая была предложена в работе Дж. Синки [5], казначейство получает доход от выполнения посреднических функций. Иными словами, существует отдельная трансфертная цена для привлекающих и размещающих ресурсы подразделений. Иные исследователи придерживаются такого мнения, что казначейство не оказывает реальных услуг клиентам, а выступает в качестве управленческого центра. В связи с этим предлагается не передавать часть процентной маржи казначейству, а производить оплату за оказанные им услуги за счет общебанковских расходов [6].

Также необходимо определить конкретные ресурсы, фондирующие активную операцию. При всем при этом необходимо обеспечить соблюдение следующих основных принципов:

- менее устойчивые пассивы должны быть размещены в более ликвидных активах;

- абсолютно все ресурсы не должны быть направлены в однотипные операции;

- ограничение среднесрочных вложений и долгосрочных вложений в том случае, когда большая 
часть привлеченных денежных средств носит в основном краткосрочный характер;

- при определении объемов ресурсов разного типа, которые фондируют данный вид активной операции, расчет должен производиться по принципу полного использования менее устойчивых пассивов.

В рамках формирования портфеля требуется провести и оценку математической связи между уровнями доходности ценных бумаг, которую именуют ковариацией. Стоит отметить, что коэффициент ковариации представляет собой произведение коэффициента корреляции и стандартных отклонений, а вместе с тем демонстрирует степень линейной зависимости случайных величин (уровни доходности отдельных бумаг). Коэффициент корреляции является относительной мерой взаимосвязи двух случайных величин (уровней доходности отдельных бумаг).

Если портфель - это объединение двух и более ценных бумаг, и активов, то математическое описание линейных зависимостей случайных величин возможно при задании набора векторов структурно отражающих количество единиц активов.

Стандартный портфель подразумевает под собой неотрицательность абсолютно всех долей активов. Стоит отметить, что инвестор по каждому приобретенному активу прибывает в длинной позиции, что в свою очередь означает покупку актива с намерением его дальнейшей продажи (закрытие позиции). Рассматриваемая покупка, как показывает практика, реализуется в процессе ожидания роста цены актива в стремлении приобрести доход от разности цен покупки и продажи.

Если относительно некоторого актива инвестор уверен в снижении его стоимости, то он обладает возможностью совершить операцию по продаже (короткая продажа), иными словами, занять короткую позицию по данному активу. Рассматриваемая операция имеет смысл в том случае, если инвестор предполагает, что ценные бумаги через определенное время упадут в цене и при возврате долга в виде определенного фиксированного количества активов он смоет приобрести их за существенно меньшую стоимость, нежели ту, кото- рая была получена при продаже в момент, следующий за моментом взятия в долг.

Инвестор, произведя операцию по продаже какого-либо актива, обладает возможностью на вырученные денежные средства совершить покупку других активов в большем количестве, нежели имел до этого. Данная операция приводит к непосредственному перераспределению стоимости активов портфеля. Таким образом, портфель инвестора изменяется как по своим стоимостным показателям, так и по своей структуре. При всем при этом, основные ограничения линейных функций не изменяются [7].

Если совершается несколько таких операций по нескольким видам таких предельно эффективных, но и рискованных ценных бумаг, то инвестиционный ресурс распределяется (диверсифицируется) между ними.

Отсюда вытекает главное практическое правило финансовых инвестиций: для повышения надежности эффекта от финансовых инвестиций в рискованные ценные бумаги необходимо делать денежные вложения не в один какой-то вид ценной бумаги, а в максимально большее разнообразие ценных бумаг, эффект от которых является случайным, но случайные отклонения при этом не считаются зависимыми. Помимо доходности риска, портфель обладает и другими значимыми параметрами. Для осуществления контроля эффективности управления инвестиционным портфелем кредитной организации требуется выполнять анализ операций с ценными бумагами.

В завершении стоит отметить, что выполнение анализа операций с ценными бумагами кредитной организации требуется для следующих целей:

- проведения оценки специфики создаваемого портфеля ценных бумаг банковской организацией, определения степени его диверсификации и уровня доходности;

- определения сформировавшихся особенностей управления портфелем ценных бумаг, а также выявления негативных моментов в действующей системе управления;

- проведения оценки уровня инвестиционного риска (риск вложений банковской организации в ценные бумаги).

\section{ЛИТЕРАТУРА}

1. Комарова А.Г., Охотников И.В., Сибирко И.В. Проблема развития инвестиционной стратегии компаний в России // Russian Economic Bulletin. 2019 . Toм 2. № 6. C. 260-263.

2. Резников А.В. Управление финансовыми инвестициями: теория и методология. Хабаровск: издательство ТОГУ, 2008. 120 с.

3. Резников А.В., Замлелая А.Т., Абросимова 0.С. Теоретические аспекты инвестиционной деятельности кредитных организаций. Intellektuelles capital — dia grudlage fur innovative entwicklung. Monographic series «European Science» Book 3. Part 1, 2020. Карлсрухе, Германия. 
4. Резников А.В., Замлелая А.Т., Абросимова О.С. Современные проблемы и пути совершенствования системы управления инвестиционной деятельностью кредитных организаций. Коллективная монография. Intellektuelles capital — dia grudlage fur innovative entwicklung. Wirtschaft, Economics, management, marketing, tourismus. «European Science» Book 3. Part 5, 2020. Карлсрухе, Германия.

5. Синки Дж. Управление финансами в коммерческом банке.-М.: Catallaxy, 2006. 1650 c.

6. Щеглова С.С. Казначейство как инструмент управления активами и пассивами банка. Научный вестник: Финансы, банки, инвестиции — 2016 — № 2. С. 103-109.

7. Шпакович Д.К., Алексашкина Е.И., Негреева В.В. Инвестиционная привлекательность предприятия и методы ее оценки // Modern Economy Success. 2019. № 3. С. 127-133.

(c) Резников Андрей Валентинович ( reznikoff_av@mail.ru ),

Замлелая Анна Тихоновна ( zamlelaia@mail.ru ), Абросимова Ольга Сергеевна ( pmabros@list.ru).

Журнал «Современная наука: актуальные проблемы теории и практики»

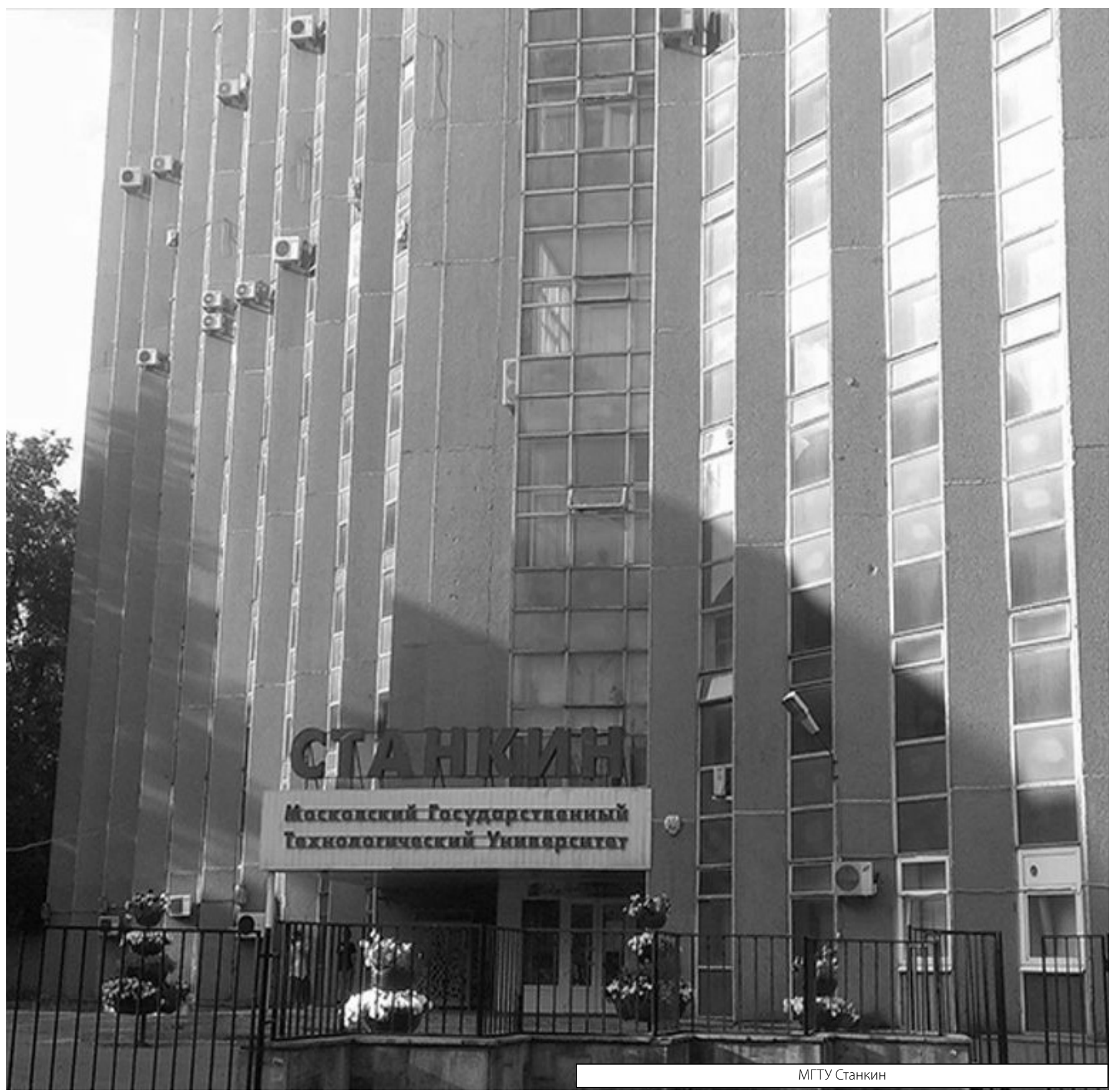

